\title{
Throughput Analysis on LTE Network for Multicast D2D System
}

\author{
Fardiansyah \\ Magister of Electrical Engineering, Faculty of Engineering, Universitas Syiah Kuala \\ Jalan Teungku Syech Abdurrauf No. 7, Darussalam, Banda Aceh, 23111, Indonesia \\ fardian.poltas@gmail.com
}

ARTICLE INFO (8 pt)

Article history:

Received

Keywords:

Device-to-Device

Point-to-Multipoint

Multicast

Mac throughput

One of the features applied to fifth generation (5G) technology is Device-to-Device (D2D) communication. The D2D communication can occur directly without going through evolved Node B (eNB). Therefore, that it can reduce traffic density on cellular network communications. However, the application of D2D communication has constrained by the limited transmission distance and multi-user service at the same source. Modelling and simulating the LTE D2D multicast network using software is an effectively and efficiently ways for analyzing mac throughput. The testing of network aims to observe and to analyze the mac throughput using two parameters, the transmission distance and the number of users, based on the utilization of the Channel Quality Indicator (CQI) index. The number of user is 20 and distance is 25 meters then mac throughput in index CQI 13 greater than CQI 4 and CQI 7 is $2150.14 \mathrm{Kbps}$. But the number of user is 20 and distance is 150 meters then CQI 13 smaller than CQI 4 and CQI 7 is $271.22 \mathrm{Kbps}$. The result of simulation shows that both distance and the number of user have influence mac throughput. The selection of CQI index is the most important factor to maintain the transmission quality and mac throughput.

Copyright (C) 2019 Politeknik Aceh Selatan. All rights reserved.

\section{Introduction}

Long Term Evolution (LTE) and LTE-Advanced (LTE-A) are an ideally candidate to provide scenario support like as smart cities, connected vehicles and device-to-device (D2D) communication [1]. LTE and LTE-A technologies get a lot of support from large commercial industries that causes the implementation of this technology running on licensed spectrum, has plug and play capabilities and has built in security features [2].

The D2D communication is a communication between user and user devices (UE) that can be directly connected both with evolved node $\mathrm{B}$ (eNodeB) like traditional cellular communication and without evolved node B [3]. From the transmission side, the D2D communication can be done in several ways using the unicast and multicast transmission system [4]. Using long distance and the large number of users cause decreasing the quality of network transmission in D2D communication system [5]. The simulation of D2D network model is an effective and efficient to evaluate the reliability of the model.

Some of advantages using D2D network are low cost, flexibility, bandwidth and battery efficiency, and high throughput. In this study, the throughput analysis of the LTE D2D communication network model uses multicast transmission system. Testing the network uses 
SimuLTE software [6] and OMNET++ [7] based on the discrete event system by considering the parameter of distance, number of users and CQI.

\section{Related Work}

In the study [8], the researcher discussed how to use the unicast transmission system on the D2D communication based on the number of users and distance to the throughput and channel quality indicator (CQI) values generated in a network scenario. In this study, the distance caused decreasing the CQI value for downlink connection above 50 meters. The greater communication distance the smaller throughput value of UE receiver media access control (MAC). The greater number of UE the smaller mac throughput.

In the study [9], the researcher discussed about the the interference effect performance of Bluetooth systems and WLAN $802.11 \mathrm{~b}$ in ad hoc networks which in the use of the same frequency spectrum will cause collisions. D2D have different method to implemented frequency reuse simultaneously as long as receiver has a considerable distance and is relatively faster it only requires one hop $[5][6]$.

\section{Method}

\section{A. Simulation scheme}

In this study, the steps of the research sheme describes in Fig. 1.

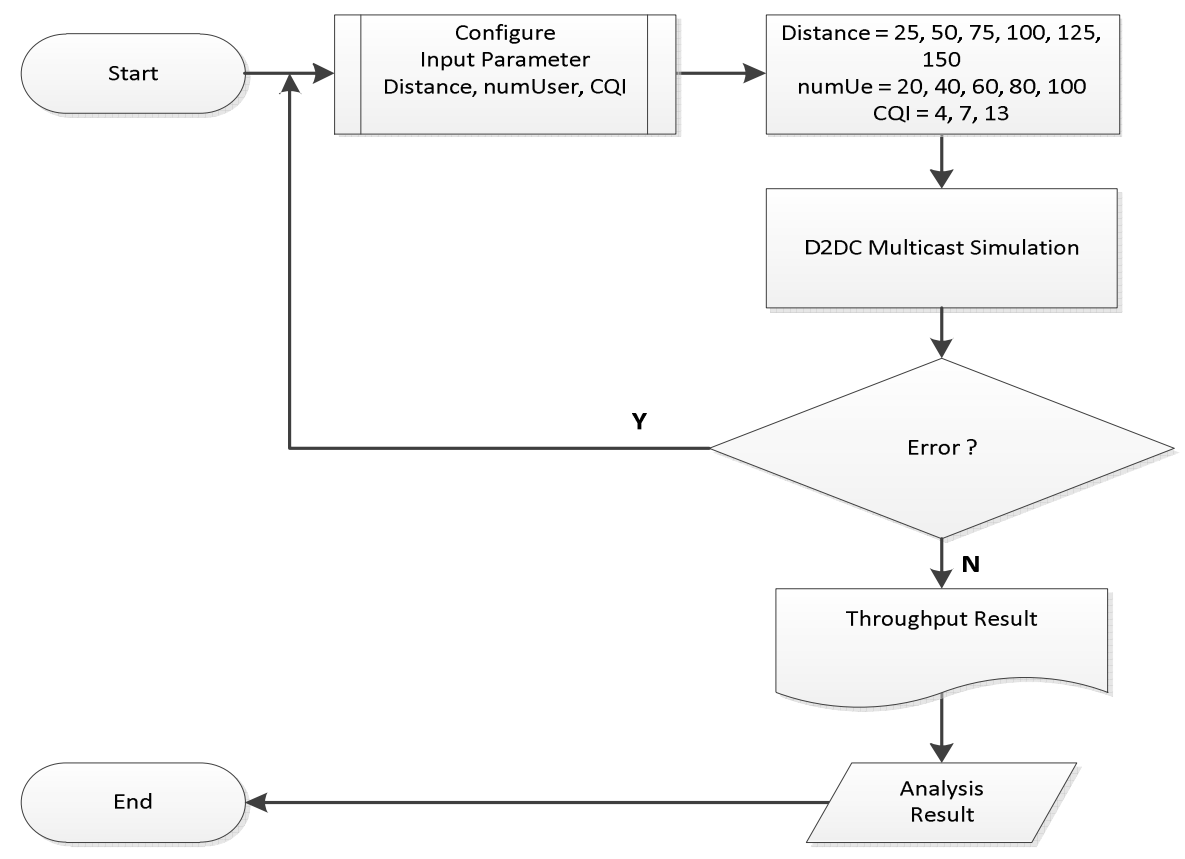

Fig. 1. Simulation scheme 


\section{B. Simulation Parameter}

The simulation parameter used in this study can be showed by Table 1 .

Table 1. Simulation Parameter

\begin{tabular}{ll}
\hline \multicolumn{1}{c}{ Parameter } & \multicolumn{1}{c}{ Value } \\
\hline D2D distance & $25 \mathrm{~m}, 50 \mathrm{~m}, 75 \mathrm{~m}, 100 \mathrm{~m}$, \\
Number of RB & $125 \mathrm{~m}, 150 \mathrm{~m}$ \\
(UL/DL)/band & $100 / 100$ \\
Number of Ue Tx/Rx & $1 /(20,40,60,80,100)$ \\
Bandwidth & $20 \mathrm{MHz}$ \\
& "Alert". One of the \\
Traffic type & application in Omnet++ \\
& supports multicast \\
Path Loss Model & ITU-R, Urban Microcell \\
Propagation Model & Rayleigh Model \\
Fading Model & Jakes \\
Noise Figure & $5 \mathrm{~dB}$ \\
Cable Loss & $2 \mathrm{~dB}$ \\
Simulation time & $60 \mathrm{~s}$ \\
\hline
\end{tabular}

\section{Simulation Scenario and Testing Type}

The scenario of testing in LTE network uses D2D multicast where one transmitter and some of receivers were designed in this network as seen in Fig. 1. The calculation of throughput in DL condition considers test parameter like as distance, numUe and CQI. The testing type can be seen in Table 2.

Table 2. Testing Type

\begin{tabular}{cl}
\hline Testing type & \multicolumn{1}{c}{ Description } \\
\hline Testing 1 & $\begin{array}{l}\text { The testing is done by comparing mac throughput value to the D2D } \\
\text { communication distance. This distance is } 25-150 \text { meters. Number of } \\
\text { user 20, 40, 60, 80, and } 100 \text { with CQI } 4 .\end{array}$ \\
Testing 2 & $\begin{array}{l}\text { The testing is done by comparing mac throughput value to the D2D } \\
\text { communication distance. This distance is } 25-150 \text { meters. Number of } \\
\text { user 20, 40, 60, 80, and } 100 \text { with CQI } 7 .\end{array}$ \\
Testing 3 & $\begin{array}{l}\text { The testing is done by comparing mac throughput value to the D2D } \\
\text { communication distance. This distance is } 25-150 \text { meters. Number of } \\
\text { user 20, 40, 60, 80, and 100 with CQI 13. }\end{array}$ \\
Testing 4 & $\begin{array}{l}\text { The testing is done by getting mac throughput average based on number } \\
\text { of Ue and comparing mac throughput value to the D2D communication } \\
\text { distance. This distance is } 25,50,75,100,125 \text { and } 150 \text { meters. Index is }\end{array}$ \\
CQI 4, CQI 7 and CQI 13.
\end{tabular}




\section{Result and Discussion}

The result of testing based on Table 2 and Fig. 1 is obtained mac throughput value for each modulation. The modulation is CQI represented by the propagation radio quality due to changes environmental condition. In this case, it is used by eNB for scheduling adjustment with modulation schemes for UE-connected channel.

Based on the simulation in Fig. 3, Fig. 4 and Fig. 5 shows average mac throughput downlink in application level. The CQI index value is permanent. This aims to know the effect of resilience and reliability of each CQI.

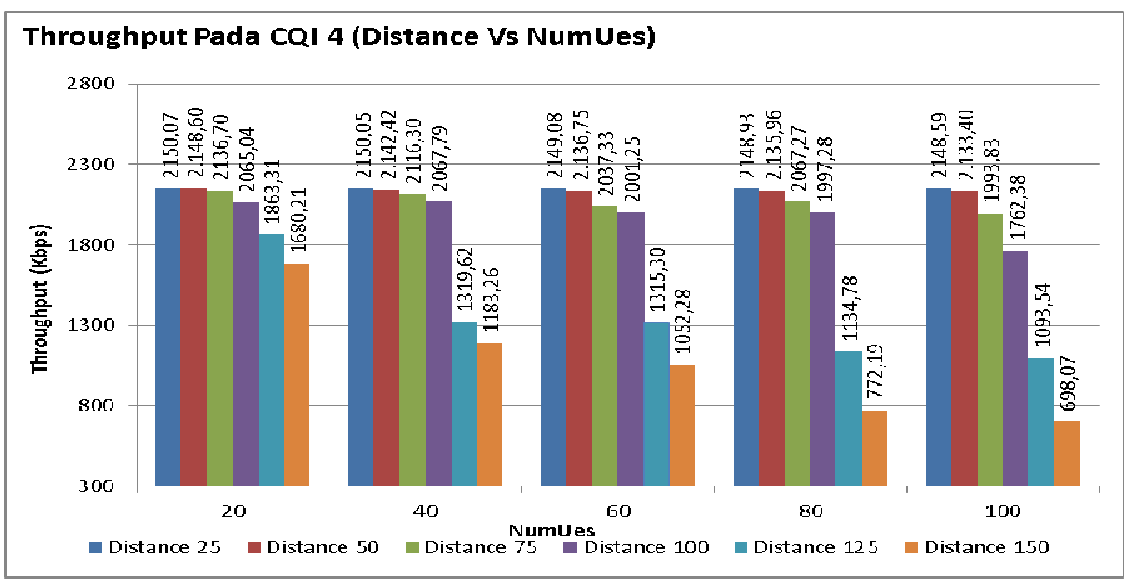

Fig. 3. Mac throughput downlink based on distance and number of users in CQI 4

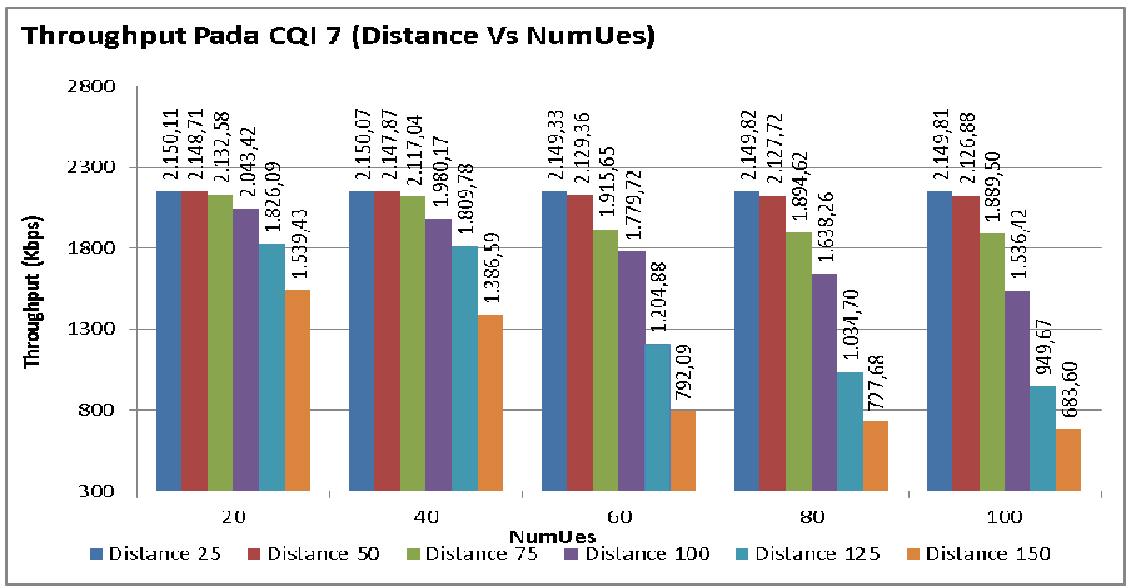

Fig. 4. Mac throughput downlink based on distance and number of users in CQI 7 


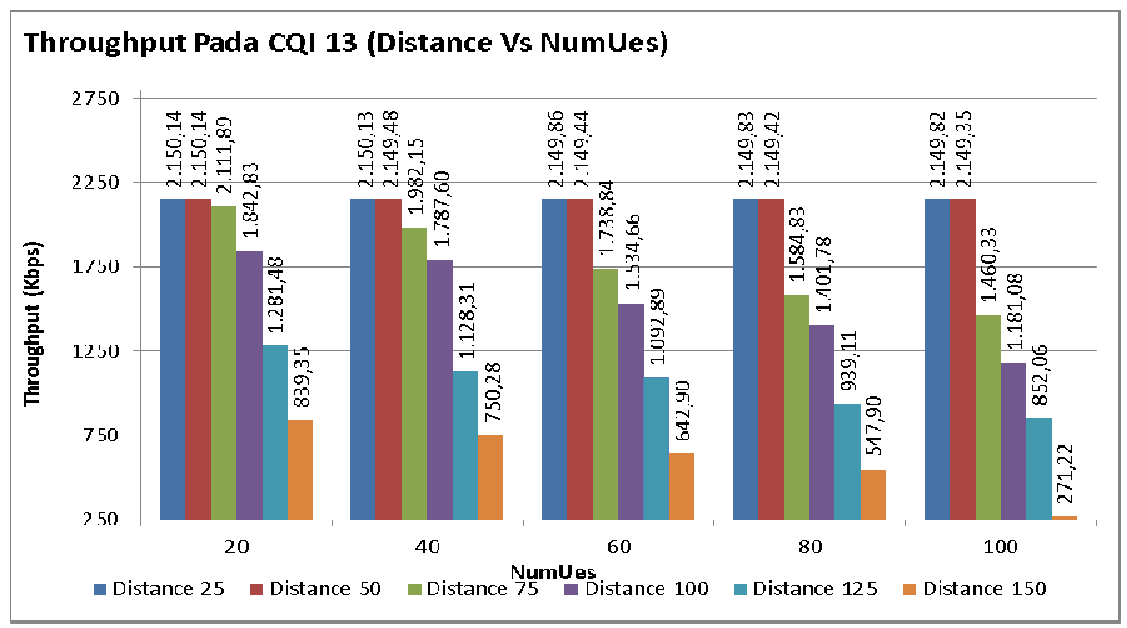

Fig. 5. Mac throughput downlink based on distance and number of users in CQI 13

In index CQI, mac throughput in downlink is not very significant based on number of users. The number of user is 20 then mac throughput is $2150.07 \mathrm{Kbps}$ and the number of user is 100 then mac throughput is $2148.59 \mathrm{Kbps}$. However, mac throughput is very significant based on distance. The number of user is 20 and distance is 25 meters then mac throughput is 2150.07. The number of user is 20 and distance is 150 meters then mac throughput is $698.07 \mathrm{Kbps}$.

The number of user is 20 and distance is 25 meters then mac throughput in index CQI 7 greater than CQI 4 is $2150.11 \mathrm{Kbps}$. The number of user is 20 and distance is 150 meters then mac throughput in index CQI 7 smaller than CQI 4 is $1539.43 \mathrm{Kbps}$.

Thus, the number of user is 20 and distance is 25 meters then mac throughput in index CQI 13 greater than CQI 4 and CQI 7 is $2150.14 \mathrm{Kbps}$. But the number of user is 20 and distance is 150 meters then CQI 13 smaller than CQI 4 and CQI 7 is $271.22 \mathrm{Kbps}$.

The effect of CQI index on transmission distance can be seen in Fig. 7 based on data sample of simulation in Fig. 1

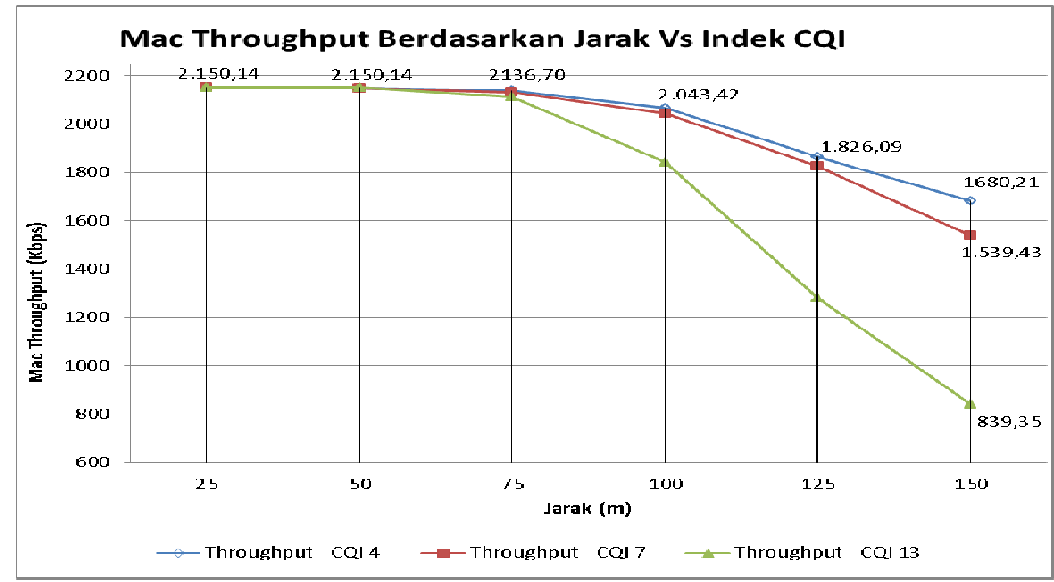

Fig. 6. The mac throughput downlink based on distance and CQI index

Based on figure 6, it can be concluded that the greater the value of the CQI index used, the smaller the mac throughput produced. on variations in the use of distance parameters from 25 meters to $150 \mathrm{~m}$, mac throughput comparisons were obtained resulting from 
differences in the use of the CQI index, 4, 7 and 13. The selection of a low CQI index such as CQI 4 has the advantage of resistance to interference due to differences in transmission distance from senders and receiver.

\section{Conclusion}

The Mac throughput generated on the LTE D2D multicast network is influenced by the transmission distance and CQI index. So that the distance and CQI index provide the large contribution to the mac throughput. While the number of user provides the small contribution to the mac throughput.

\section{References}

[1] M. Usman, F. Granelli, M. Rizwan Asghar, "5G and D2D Communications at the Service of Smart Cities", John Wiley \& Sons Ltd, 2019.

[2] G. Nardini, A. Virdis \& G. Stea, "Modeling Network-Controlled D2D Communications in SimuLTE", Sensors, MDPI, 2018.

[3] 3GPP - TS 36.843 v12.0.1, "Study on LTE Device-to-device Proximity Services: Radio aspecs (Release 12)", March 2014.

[4] Antonio Virdis, Giovani Nardini, Giovani Stea, "Simulating device-to-device communications in OMNeT++ with SimuLTE: scenarios and configurations," OMNeT++ Community Summit 2016, Brno, CZ, September 15-16, 2016

[5] Rifki, Y. Rahayu, A. Virdis, "Pengaruh Penambahan Jumlah User dan Jarak pada Komunikasi D2D Unicast dengan SimuLTE", Jom FTeknik Volume 5 No.1 Januari s/d Juni 2018.

[6] SimuLTE. LTE user plane simulation model for INET \& OMNET++, [Online] tersedia di : www.simulte.com., diakses January 2019.

[7] Omnet++, An object oriented modular discrete event network simulation framework, 2016. [Online] tersedia di : https://omnetpp.org., diakses January 2019.

[8] 3GPP - TS 36.843 v12.0.1, "Study on LTE Device-to-device Proximity Services: Radio aspecs (Release 12)", March 2014.

[9] Cristopher Cox, "An Introduction to LTE", John Wiley \& Sons Ltd, ISBN-9781119970385, 2012.

[10] A. Insani, "Pengaruh Performansi Akibat Interferensi Pada Sistem Bluetooth dan WLAN 802.11B", Buletin Pos dan Telekomunikasi, Vol. 9 No. 4 Desember 2011.

[11] A.Virdis, G.Nardini, G.Stea, "Modeling unicast device-to-device communications with simuLTE", 1st International Workshop on Link and System Level Simulation (IWSLS), IEEE 2016.

[12] Peterson, L. L., and Davie, B. S. Computer Networks : a systems approach (Morgan Kaufmann). 1996. ISBN: 1-55860-368-9 (Paperback ISBN: 1-55860-404-9 ) pp 94-95.

[13] H.C. Lee, "A Mac Throughput in the Wireless LAN", in Advance Wireless LAN, ISBN : 978-953-510645-6, 2012. 